DOI: https://doi.org/10.24867/04FA13Markovic

\author{
PREUREĐENJE FUTOŠKE PIJACE U NOVOM SADU \\ REARRANGENMENT OF „FUTOŠKA“ MARKET IN NOVI SAD \\ Olivera Marković, Marko Todorov, Fakultet tehničkih nauka, Novi Sad
}

\section{Oblast - ARHITEKTURA}

Kratak sadržaj - Ukoliko želite da upoznate duh nekog grada, idite na pijacu, tamo se najbolje vidi ekonomska moć, navike i kultura njegovih stanovnika. Istraživački rad bavi se samim programom pijace uzimajući u obzir istorijski aspekat $i$ aktuelne teme. Rad pristupa rešavanju problema poput ishrane stanovnika u velikim gradovima $u$ budućnosti $i$ bavi se konceptom urbane agrokulture $u$ javnim objektima, koji bi mogao da se primeni $i$ na drugim javnim objekatima u Novom Sadu. Projekat je zamišljen kao pokretač ove ideje za dalji razvoj $i$ na drugim projektima.

Ključne reči: Pijaca, ishrana stanovnika, agrokultura

Abstract - If you want to discover the spirit of a city, go to the market, there you can see, in the best manor, the economic power, habits and culture of the citizens. The research paper deals with the markets program taking into consideration the historical aspects and modern topics. The paper tackles the food related problem of citizens in future big cities and deals with urban agricultural concept in public residence, which can also be used on other public structures in Novi Sad. The project is designed as an initiator of the idea for further development on other projects.

Key words: Market, food related problems, agriculture,

\section{UVOD}

Proteklih godina savremeni gradovi se susreću sa sve većim problemima ishrane stanovništva, ideje za borbu protiv ovakvih problema već postoje, koncept urbanog uzgajanja biljaka je već primenjen u svetskim projktima i ispostavio se kao funkcionalan.

Ovaj koncept uvršten je u projekat preuređenja Futoške pijace u Novom Sadu. Trenutna pijaca zadovoljava određen nivo potreba stanovništva grada, međutim, njena neatraktivna spoljašnjost, slaba funkcionalnost, zatvorenost prema ulici, prenatrpanost robom, ljudima i neorganizovanim sadržajima, utiče na njenu sveukupno lošu sliku.

Veoma bitan objekat smešten u samom čvorištu grada zahteva pažljivije planiranje, atrktivniju, uređeniju spoljašnjost i funkcionalnost od trenutne, čime se ovaj rad i bavi.

\section{NAPOMENA:}

Ovaj rad proistekao je iz master rada čiji je mentor bio dr Marko Todorov, docent.

\subsection{Zadatak i cilj projekta}

Zadatak projekta jeste oblikovanje novog objekta na mestu već postojeće pijace u cilju boljeg funkcionisanja, zadovoljenja budućih potreba grada koji se širi, obuhvatanja većeg broja funkcija u okviru jednog objekta. Ideja rada je da se pored klasične prodaje namirnica koja već postoji na ovom mestu uvede i program uzgajanja hrane na samom mestu prodaje.

Proteklih godina savremeni gradovi se susreću sa sve većim problemima ishrane stanovništva, ideje za borbu protiv ovakvih problema već postoje, koncept urbanog uzgajanja biljaka je već primenjen u svetskim projktima i ispostavio se kao funkcionalan. Uvrštavanje ovakvog sadržaja može pre svega znatno podići svest građana o ideji urbane agrokulture, doprineti edukaciji stanovništva o ovom konceptu, kao i samoj atraktivnosti objekta, kako vizuelno, tako i konceptom.

Cilj rada je zadovoljenje što većeg broja potreba građana koje se tiču hrane na jednom mestu. Pored osnovnih sadržaja koje obuhvata jedna pijaca fokus je na multifunkcionalnosti, kombinaciji sadržaja i atraktivnosti samog objekta obzirom na njegovu lokaciju i važnost $u$ čitavoj urbanoj strukturi grada.

\subsection{Metodologija i pristup projektovanju}

Nakon analize same lokacije, određivanju njene važnosti u celokupnoj urbanoj matrici grada, pristupljeno je utvrđivanju sistema odluka koje dovode do finalnog projekta. Istraživanjem istorijskog razvoja pijace i mesta na kome se ona danas nalazi, utvrđeno je da je lokacija idealna za ovu vrstu programa. Udaljenost od centra i ustaljene navike korisnika da odlaze u kupovinu baš na tom mestu, ističu se kao prednost.

Kroz analizu lokacije, istorije samog mesta i trenutne situacije utvređeni su osnovni obrisi projekta. Ideja je bila otvorenost pijace ka ulici, čime bi se dobila bolja osvetljenost, širi prolazi, obuhvatanje više manjih tezgi u jednu veću, čime se dobija manji broj tezgi zarad dobijanja fluidnijeg i provetrenijeg prostora. Kroz istraživanje o aktuelnostima $\mathrm{u}$ arhitekturi projekatom su obuhvaćeni pojmovi poput urbane agrokulture, multifunkconalnosti prostora i mešavine različitih funkcionalnih programa.

Ovim projektom podiže se kvalitet urbane celine dela grada na raskrsnici Bulevara Oslobođenja i Jevrejske ulice, kao i kvalitet usluge same pijace. Grad dobija obogaćenje novim sadržajima i uvođenje novog koncepta agrokulture u javnim objektima prvi put u Novom Sadu. 


\section{ANALIZA PROGRAMA I KONTEKSTA}

\subsection{Potrebe savremenog čoveka}

Ljudi svojim prisustvom, izgledom, aktivnostima, običajima i kulturom doprinose formiranju specifičnog identiteta i prepoznatljivosti prostora na kome žive. Oni formiraju i čuvaju naselje, grade objekte i prostor prilagođavaju svojim potrebama. Potrebe savremenog čoveka od dvadesetog veka do danas u svojoj osnovi imaju isti karakter ali sa razvojem savremenih tehnologija i sam način života je evoluirao. Obzirom da živimo u vremenu kada su nam osnovne potrebe pretežno zadovoljene, ljudska vrsta teži ka višim nivoima potreba u smislu razvijanja na svim poljima u svrhu poboljšanja kvaliteta života.

\section{2. Žižne tačke u urbanom tkivu}

Žižne tačke su najznačajnija mesta ili elementi u naselju, koje se izdvajaju prema određenim karakteristikama u odnosu na neposredno okruženje. To su delovi naselja koji se najlakše prepoznaju po prisustvu velikog broja ljudi, karakteriše ih dinamika, frekventnost i aktuelnost. To su najposećenija, najprivlačnija i najznačajnija mesta u urbanom tkivu. Primer takvih mesta su trgovi, autobuske stanice, tržnice, tržni centri i drugo. [1] Veoma je važno prepoznati šta su žižne tačke u prostoru i ukoliko se bavimo njihovim oblikovanjem, bitno je promisliti sve elemente, kao i efekat koji želimo da postignemo na kraju.

Futoška pijaca u Novom Sadu, kojom se ovaj rad bavi, svakako predstavlja veoma bitnu žižnu tačku grada. Projektovanjem ovako važnog objekta ne utičemo samo na neposrednu okolinu objekta već i na čitavu urbanu strukturu. Bitno je dobro razmotriti sve faktore: saobraćajne, morfološke, sociološke, društvene, tehnološke, ekološke i druge. Da bi se dobilo kvalitetno rešenje pored arhitekture, veoma važnu ulogu igra i dobra organizacija samog programa. Kombinacija više sadržaja može privući različite grupe korisnika i na taj način se može obezbediti živost date lokacije.

\section{TEORIJSKE OSNOVE}

\subsection{Pijaca kao fenomen}

Pijace nastaju kada i prve robne razmene, odnosno kada ljudi postaju svesni činjenice da nečega imaju više nego što im treba, a nečega manje ili uopšte nemaju. Spontano su se formirala mesta razmene dobara. Prvi istorijski oblici pijačne delatnosti su vašari, njihov intenzivniji razvoj beleži se u 18 . veku. Ovakav tip razmene dobara se u nekim sredinama i do danas održao kao deo tradicije okupljanja ljudi, najčešće nedeljom ili u vreme verskih praznika. Od nastajanja do danas pijace su pokazatelj društveno-ekonomskih prilika.

Tržišne promene, po nepisanom pravilu, prvo uočavaju prodavci na pijacama. Direktan i neposredni kontakt prodavaca i kupaca je jedna od ključnih osobina pijace koja ih razlikuje u odnosu na druge, savremene oblike trgovine. Pijaca je tržište, prostor gde se ljudi okupljaju i komuniciraju, kako u ruralnim tako i u gradskim sredinama. Upravo zbog komunikacije ljudi na tržnici ona ima i ozbiljan sociološki aspekt. Sve navedene osobine i karakteristike pijace imaju korene u bogatoj istoriji i tradiciji ove delatnosti koja se na ovim prostorima neguje vekovima [2].
Savremeno doba donosi fenomen supermarketa i megamarketa koji nude stanovništvu alternativu kupovini na pijacama, koja je do tada bila dominantna. Upravo zbog ovakvih događanja kao direktna posledica, dolazi do promena u pijačnoj delatnosti.

\subsection{Problemi prehrane urbanog stanovništva u gusto naesljenoj sredini}

Procesom urbanizacije i industrijalizacije šire se obodi gradova i okolna polja koja su nekada služila za poljoprivredu pretvaraju se u stambene, poslovne i industrijske zone zone, a sve u cilju zadovoljenja potreba gradova. Pojas plodnog tla oko gradova se sve više smanjuje što direktno utiče na proizvodnju hrane. I dok sa jedne strane gradovi svojim širenjem zadovoljavaju određene potrebe samog grada, druge čak i primarne potrebe kao što je ishrana tog novonaseljenog stanovništva, bivaju zapostavljene.

Proizvodnja hrane u samim gradovima XXI veka se sve više smanjuje ili je uopšte i nema. Hrana se proizvodi na drugim mestima, u ruralnim predelima koja usled širenja gradova bivaju sve dalje, samim tim se povećavaju troškovi transporta kao i vreme koje je potrebno da hrana dospe od proizvodnje do domaćinstava. Ovim se stvaraju problemi poput propadanja hrane usled dugog ili neadekvatnog transporta i skladištenja, kao i povećanja cena finalnog proizvoda

Ubrzano širenje gradova nosi sa sobom dugačak spisak problema. Način da se neki od problema koji se tiču ishrane reše jesu razvojne strategije gradske vlasti, podsticanje proizvodnje hrane na selu i obezbeđivanje odgovarajućeg pristupa toj hrani, kao i podsticanje novih projekata sa idejama razvoja proizvodnje hrane u samom gradu.

Omogućavanje prodaje hrane proizvdene na taj način i razvijanje strategija tako da se taj koncept rasprostrani kako po samom gradu, tako i u drugim gradovima. Uspostavljanje mehanizma funkcionisanja ovakvog koncepta.

\subsection{Urbana agrokultura}

Urbana poljoprivreda (urban agriculture) je poljoprivredna grana koja se odnosi na uzgajanje, preradu i distribuciju hrane $\mathrm{u}$, ili u neposrednoj blizini naseljenih mesta. Lokalna proizvodnja hrane za lokalnu upotrebu je osnovna karakteristika urbane agrokulture. To je zatvoren sistem snabdevanja u okviru lokalne zajednice koji pruža mnoge prednosti poput rekultivacija neuređenih gradskih površina, zapošljavanja stanovništva, više hrane i zdravija ishrana, povećanje ekonomske moći grada i njegovih stanovnika.

Urbana agrokultura doprinosi ekonomskoj moći grada jer se pare ne odlivaju za dopremanje ili uvoz prehrambenih proizvoda. Lokalno uzgajanje hrane, ne samo da pospešuje ekonomiju gradova i ekonomski položaj lokalnog stanovništva, već u velikoj meri utiče i na ekonomsku snagu države, ali i ekološku sliku planete. Dakle, doprinosi ekonomskom rastu grada kroz proizvodnju, preradu, pakovanje i distribuciju prehrambene robe, ali i posredno, kroz očuvanje ekonomske moći stanovništva kroz uštede. 
Ovaj proces pokreće i druge grane privrede (proizvodnja humusa, građevinske pripreme površina za uzgoj hrane, itd), i otvara nova, lokalna, radna mesta. Ovo, zatim, doprinosi smanjenju cene hrane usled manjeg transporta ali i dostupnosti sveže hrane za stanovništvo u gradovima. Stanovništvu ostaje više novca za kupovinu proizvoda koje ne mogu napraviti sami [3].

Gradovi u Srbiji postaju sve naseljeniji a potražnja za hranom je sve veća, bitno je razmišljati o uvođenju ovakvih principa dok još nije došlo do realnih problema. Sa strategijama nikada nije prerano krenuti, pre svega bitno je razmišljati o najmlađima i usaditim im ovakve ideje od malih nogu, tako da mogu da sažive sa njima.

Društvo sjajno napreduje kada starci sade drveće, a znaju da u njihovoj senci nikada neće sedeti-grčka poslovica.

\section{PROJEKAT PIJACE}

\subsection{Projektni zadatak}

Na mestu već postojeće Futoške pijace u Novom Sadu, potrebno je osmisliti projekat novog objekta koji će zadržati svoju osnovnu namenu pijace uz dodatak i kombinaciju drugih programa. Poželjno je kombinovati više različitih programa ali tako da jedna drugu ne ugrožavaju i da objekat može da funkcioniše kao celina. Treba obratiti pažnju na odnos objekta prema ulici, odnosno prema raskrsnici. Kretanje ljudi kao i funkcionalnost same pijace moraju biti ispoštovani. Voditi računa o atraktivnosti lokacije, iskorišćenju zemljišta kao i atraktivnosti samog rešenja koje se nalazi na bitnoj lokaciji u gradu. Pažljiva upotreba materijala, osvetljenja i drugih enterijerskih elemenata može znatno doprineti kvalitetu rešenja. Potrebno je razmišljati o korišćenju pijace u toku celog dana, ne samo u prepodnevnim časovima kada je pijaca aktivna.

\subsection{Funkcionalna organizacija}

Pri projektovanju cilj je bio isprojektovati objekat koji je otvoren prema ulici, tako da pijaca može da oživi kao potpuno javni prostor. Ovim potezom privlači se veći broj posetioca, prateći sadržaji bili bi posećeniji a pijaca bi sama po sebi postala atrakcija. Dodatnu atraktivnost projektu donose vertikalne bašte $u$ kojima se uzgaja začinsko bilje i različite kulture koje mogu da uspevaju u datim uslovima uzgajanja. Vertikalnoj bašti koja se nalazi na samoj fasadi konstrukcije pijace pristupa se posebnim pristupnim stazama kako bi biljke mogle uredno da se održavaju.

U zavisnosti od kultura koje bi se uzgajale kao i od godišnjeg doba fasada pijace bila bi promenljiva. Organizacija ispod krova pijace je takva da su pešački koridori između tezgi dovoljno veliki i funkcionalni za nesmetan prolazak posetioca. Ideja je bila spajanje više tezgi u jednu veću, čime se dobija omanji kiosk na kome bi se prodavale namirnice. Ideja urbane agrokulture prenosi se i na sam detalj rešavanja tezgi, pa se na njihom krovovima, takođe, uzgajaju biljke koje doprinose opštoj atmosferi i mikroklimi pijace.

U prednjem delu pijace na ulazu iz Jevrejske ulice, nalazi se dugački šank i slobodni stolovi. Ovaj deo zamišljen je kao niz kafića sa različitim konceptima pronude jedan do drugog što se nadovezuje na široku ponudu i šarenilo pijace. Slobodni stolovi i stolice upućuju na što veću socijalizaciju ljudi, slobodu kretanja i izbora, što stvara utisak potpuno javnog prostora. U zatvorenim delovima pijace nalaze se programi poput restorana sa delikatesima. Deo gde se prodaju ceđeni sokovi, sveže salate i sve što se zapravo uzgaja na samoj pijaci uz mogućnost konzumacije. Iz ovog dela nastavlja se u deo gde se nalaze dugački stolovi koji su slobodni i gde može da se sedi kako bi se konzumiralo sve što se nudi u prethodnoj prostoriji.

Dugački slobodni stolovi upućuju na zajedništvo, viši stepen socijalizacije i odaju utisak prisnije atmosfere, koja generalno nedostaje javnim prostorima. Iako se u objektu nalazi veliki broj različitih programa oni su raspoređeni i usaglašeni tako da funkcionišu kao jedna velika celina. S obzirom da cela organizacija programa zavisi od posećenosti koja bi uticala na ekonomsku održivost ovog projekta, ova pijaca se može posmatrati kao živ organizam koji se stalno menja u zavisnosti od odnosa ponude i potražnje, a ova karakteristika je i u srži samog programa pijace. Dakle, živost pijace kao programa, prenosi se i na samu funkcionalnu organizaciju čitavog projekta.

\section{ZAKLJUČAK}

Iz analize postojećeg stanja Futoške pijace izveden je zaključak da je reinterpretacija ovog prostora neophodna. Atraktivna lokacija na raskrsnici bitnih saobraćajnica $u$ Novom Sadu bio je poseban izazov za projektovanje i za uređenje enterijera specifičnog programa pijace. Kako bi se podigao kvalitet i nivo usluge, bilo je neophodno dobro promisliti funkcionisanje pijace od dopremanja hrane, preko izlaganja proizvoda do završetka lanca i čišćenja pijace.

Uvođenjem novih programa poput urbane agrokulture projekat je dobio na dodatnom kvalitetu. Osim funkcionalne uloge koju ima bilje uzgajano u sklopu objekta pijace, ono ima estetsku, edukativnu i pokretačku ulogu. Estetska uloga ispoljava se na fasadama objekta, gde su biljke u jednom segmentu potpuno izložene prema ulici, tako da osim što učestvuju u enterijeru pijace, učestvuju i $\mathrm{u}$ formiranju uličnog fronta.

Edukativna i pokretačka uloga ispoljava se u tome što bi ovo bio jedan od pilot projekata sa konceptom agrikulture $\mathrm{u}$ javnom objektu. Uvođenje programa uzgajanja biljaka $\mathrm{u}$ urbanom okruženju ima za zadatak da pokrene i druge javane objekte da pristupe ovom modernom konceptu, koji je u svetu već odavno zaživeo.

Ostali aspekti projekta poput ugostiteljskih sadržaja i delova objekta namenjenih za konzumaciju proizvoda, imaju za zadatak da naglase socijalni karakter pijace kao javnog prostora.

Prostor koji je definisan projektom uobličava i unapređuje već postojeći program pijace na ovom mestu. Ubacivanjem dodatnih sadržaja koji su usko vezani za hranu, njenu proizvodnju, prodaju i konzumaciju, svrstava ovaj hribrid u svojevrsnu tipologiju tržnog centra koji je posvećen hrani. Ono po čemu bi se ova pijaca izdvajala jeste široka ponuda različitih sadržaja, inovativan i moderan koncept, sklopljen u jednu veliku celinu.

Specifičnost proizvoda, atraktivnost samog objekta $u$ estetskom i u konceptualnom smislu privukao bi veliki broj posetioca, ne samo građana, već bi se lokacija izdvojila i kao turistička atrakcija. Poseta ovoj pijaci 
posetiocima ne bi pružila samo monotono nabavljanje namirnica, već kompletno iskustvo. Pružala bi im se mogućnost posmatranja modernih tehnologija uzgajanja biljaka u urbanim uslovima, kao i konzumacija istih tih proizvoda na licu mesta.

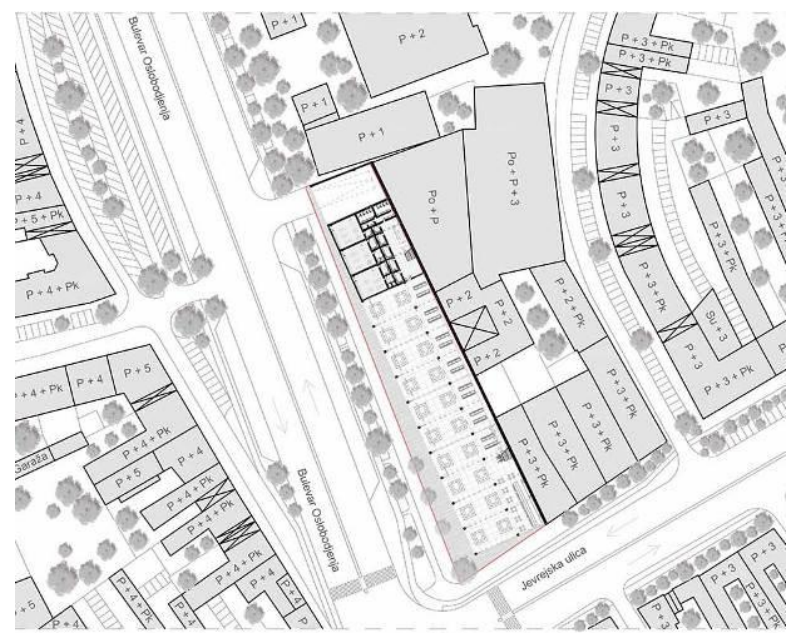

Slika 1. Situacija novoprojektovane Futoške pijace

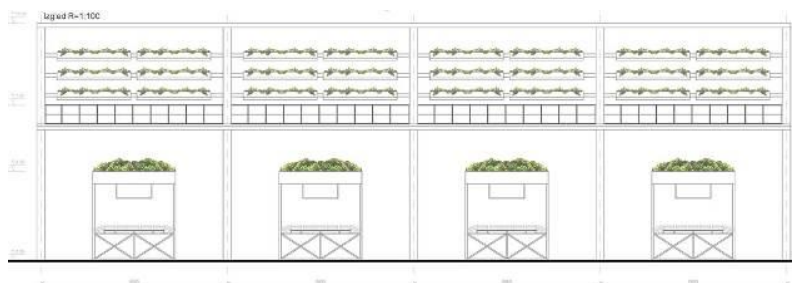

Slika 2. Presek novoprojektovane Futoške pijace

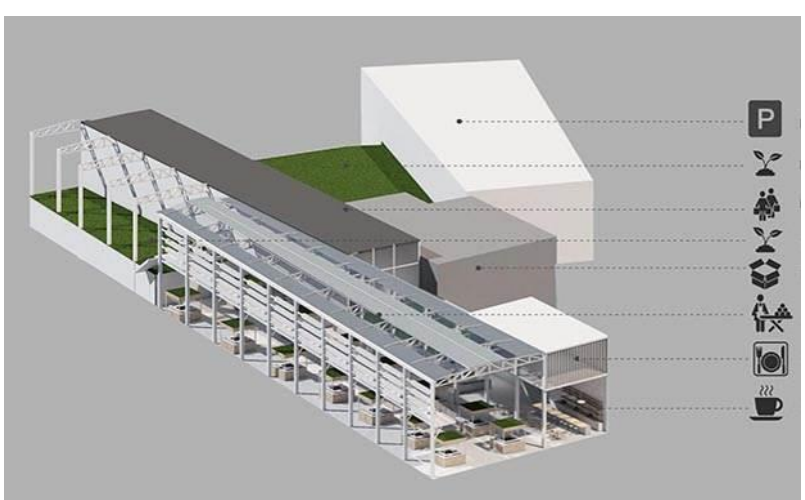

Slika 3. Dijagram novoprojektovane Futoške pijace

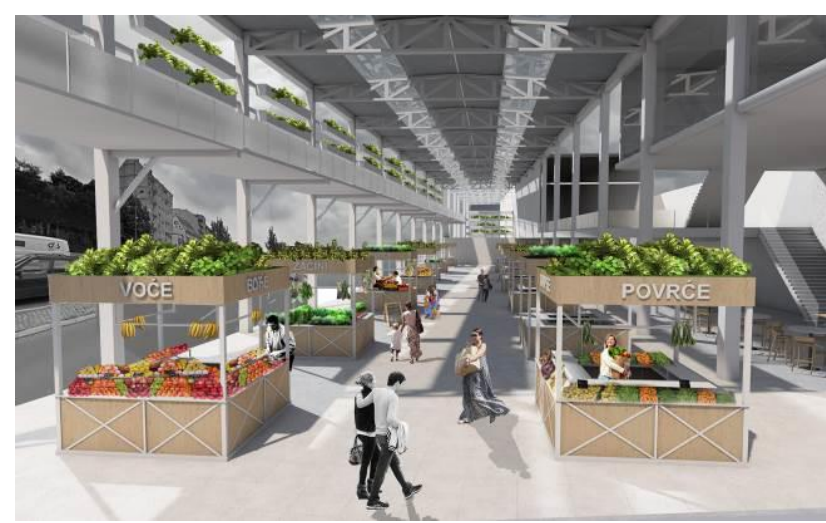

Slika 4. Vizualizacija novoprojektovane Futoške pijace

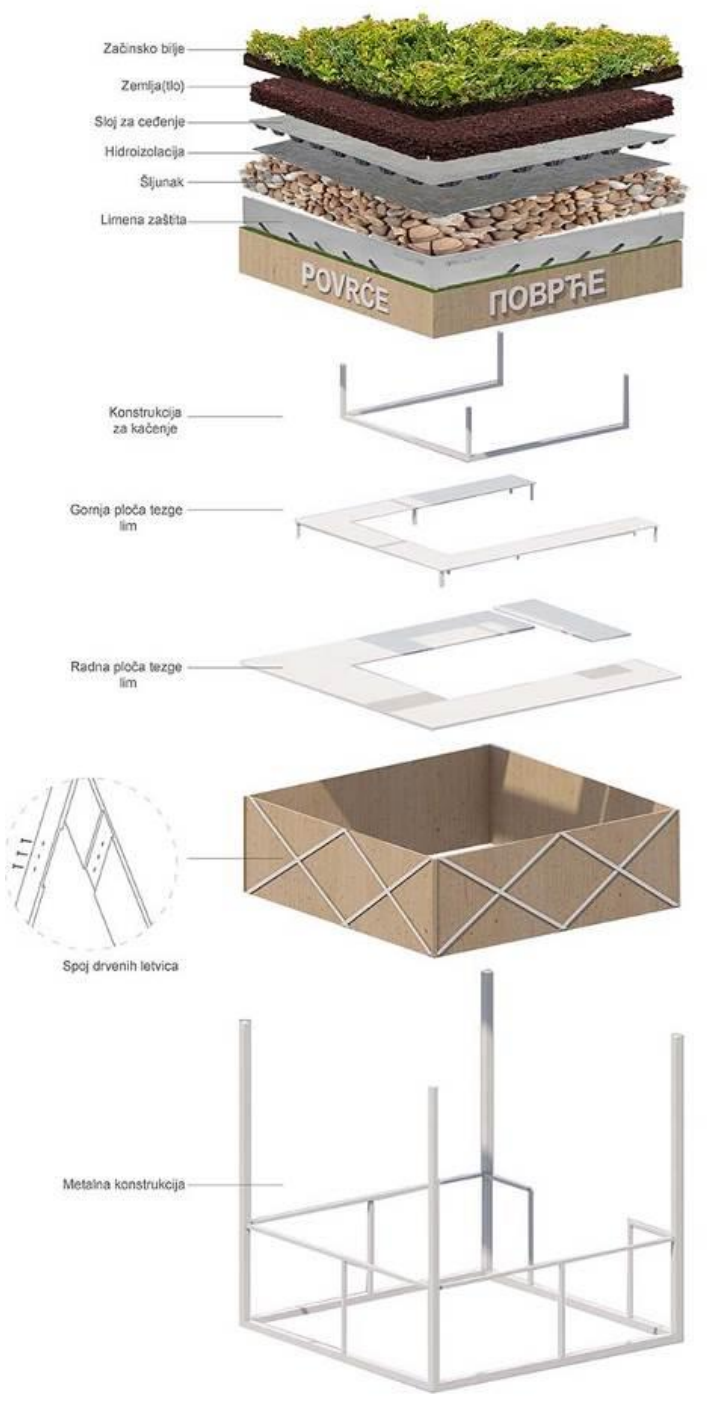

Slika 5. Detalj tezge na novorpojektovanoj Futoškoj pijaci

\section{LITERATURA}

[1] Vukajlov, Lj: Uvod u urbanizam, Fakultet Tehničkih Nauka, Novi Sad, 2014.

[2] Savo Duvnjak, izvršni direktor Poslovnog udruženja „Pijace Srbije“,Poslovno udruženje „Pijace Srbije“, 2013. godine; https://www.pups.rs/docs/pravci_razvoja_pijacne_dela tnosti.pdf , (pristup 3.5.2019.)

[3] Autor teksta: Iva Sučević dipl. inž. arh., 15.10.2018.; https://arhingreen.rs/urbana-agrokultura-neiskoriscenipotencijal/ , (pristup 3.5.2019.)

\section{Kratka biografija:}

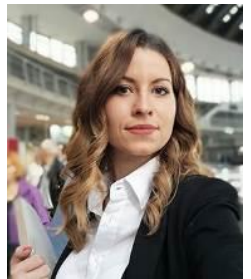

Olivera Marković, rođena je u Novom Sadu 1994. god. Osnovne akademske studije završila je 2018. god na Fakultetu tehničnih nauka u Novom Sadu, na kom brani i master rad 2019. godine iz studijskog programa Arhitektura- oblast Dizajn enterijera. 